\title{
Low-intensity laser phototherapy enhances the proliferation of dental pulp stem cells under nutritional deficiency
}

\section{Cacio MOURA-NETTO(a) \\ Leila Soares FERREIRA ${ }^{(b)}$ \\ Carlos Magno MARANDUBA(c) \\ Anna Carolina Volpi \\ MELLO-MOURA ${ }^{(b)}$ \\ Marcia Martins MARQUES(d)}

(a) Universidade Cruzeiro do Sul, School of Dentistry, São Paulo, SP, Brazil;

(b) Universidade Ibirapuera, School of Dentistry, São Paulo, SP, Brazil;

(c) Universidade Federal de Juiz de Fora, Institute of Biological Sciences, Department of Biology, Juiz de Fora, MG, Brazil;

(d) Universidade de São Paulo (USP), School of Dentistry, Department of Restorative Dentistry, São Paulo, SP, Brazil.

Declaration of Interests: The authors certify that they have no commercial or associative interest that represents a conflict of interest in connection with the manuscript.

\section{Corresponding Author:}

Cacio Moura-Netto

E-mail: caciomn@usp.br

DOI: 10.1590/1807-3107BOR-2016.vol30.0080

Submited: Nov 07, 2015

Accepted for publication: Mar 16, 2016

Last revision: Apr 26, 2016
Abstract: Dental trauma in immature permanent teeth can damage pulp vascularization, which leads to necrosis and cessation of apexogenesis. Studies on tissue engineering using stem cells from human exfoliated deciduous teeth (SHEDs) have yielded promising results. Laser phototherapy (LPT) is able to influence the proliferation and differentiation of these cells, which could improve tissue engineering. SHEDs (eighth passage) were seeded into 96-well culture plates $\left(10^{3}\right.$ cells/well $)$ and were grown in culture medium supplemented with 15\% defined fetal bovine serum (FBS) for $12 \mathrm{~h}$. After determining the appropriate nutrition deficiency status (5\% FBS), the cells were assigned into four groups: 1) G1 - 15\% FBS (positive control); 2) G2 - 5\% FBS (negative control); 3) G3 - 5\% FBS+LPT $3 \mathrm{~J} / \mathrm{cm}^{2}$; and 4) G4 - 5\% FBS+LPT $5 \mathrm{~J} / \mathrm{cm}^{2}$. For the LPT groups, two laser irradiations at $6 \mathrm{~h}$ intervals were performed using a continuous wave InGaAlP diode laser $\left(660 \mathrm{~nm}\right.$, with a spot size of $\left.0.028 \mathrm{~cm}^{2}, 10 \mathrm{~mW}\right)$ in punctual and contact mode. Cell viability was assessed via an MTT reduction assay immediately after the second laser irradiation $(0 \mathrm{~h})$ and 24, 48, and $72 \mathrm{~h}$ later. We found that G3 and G4 presented a significantly higher cell growth rate when compared with $G 2(p<0.01)$. Moreover, G4 exhibited a similar cell growth rate as G1 throughout the entire experiment $(p>0.05)$. These findings indicate that LPT with $5 \mathrm{~J} / \mathrm{cm}^{2}$ can enhance the growth of SHEDs during situations of nutritional deficiency. Therefore, LPT could be a valuable adjunct treatment in tissue engineering when using stem cells derived from the dental pulp of primary teeth.

Keywords: Stem Cells; Laser Therapy; Low-Level Light Therapy; Dental Pulp; Tissue Engineering; Endodontics.

\section{Introduction}

Dental trauma in immature permanent teeth can damage pulp vascularization and lead to necrotic conditions and cessation of the dental root formation process. ${ }^{1,2}$ For many decades, the treatment of choice for such conditions was the induction of apexification using a calcium hydroxide dressing. Later, the placement of MTA (mineral trioxide aggregate) plugs in the apical area was also indicated. ${ }^{3}$ The cellular therapy with the purpose 
of creating new pulp tissue in these teeth was able to allow the maintenance of root formation to finalize this process. ${ }^{4,5}$ Recently, studies in tissue engineering have been performed to elucidate the mechanisms of stem cell proliferation and differentiation for future use in cellular therapy. ${ }^{6}$ Several studies have shown that undifferentiated cells from the dental pulp can act as stem cells, capable of differentiating into other cell types. ${ }^{78}$ Therefore, there is a great potential for these dental pulp stem cells (DPSCs) and stem cells from human exfoliated deciduous teeth (SHEDs) in the treatment of pulpless immature permanent teeth with incomplete root formation. . $^{3,10,11}$ Another therapy that could be combined with cellular therapy is laser phototherapy (LPT). ${ }^{12}$ Indeed, studies on LPT have demonstrated its capability of modulating cell growth, viability, and differentiation, as well as the protein synthesis and secretion processes of several cell types (e.g., fibroblasts, osteoblasts, and endothelial cells) ${ }^{13,14,15,16,17,18,19}$ It is important to state that the increase of cell viability is a major issue for stem cells, primarily when the objective of stem cell culture is to implant them into human organs during cellular therapy. Several in vitro studies have already explored the effects of LPT on mesenchymal stem cells (derived from bone marrow and fat tissue). ${ }^{20,21,22}$

However, little is known regarding the effects of LPT on the biology of SHEDs. Determining how to stimulate stem cells to proliferate and differentiate could improve the future use of these cells in dental tissue regeneration. Therefore, the objective of this study was to evaluate the influence of LPT on cellular growth of a dental pulp stem cell lineage originating from deciduous teeth (SHED cell line).

\section{Methodology}

\section{Cell culture}

This study was previously approved by the Universidade de São Paulo Ethical Committee (Protocol 161/2009). Dental pulp stem cells originating from exfoliated deciduous teeth (PDH7 cell lineage previously characterized as stem cells) were donated by Prof. Carlos Maranduba from Juiz de Fora University. Cells grown in the sixth and seventh passages were cultured in DMEM/Ham's F-12 culture media (1:1;
Invitrogen, Carlsbad, USA) supplemented with 15\% defined fetal bovine serum (Hyclone, Logan, USA), $100 \mathrm{U} / \mathrm{mL}$ penicillin (Invitrogen), $100 \mathrm{mg} / \mathrm{mL}$ streptomycin (Invitrogen), $2 \mathrm{mmol} / \mathrm{L}$ L-glutamine (Invitrogen), and $2 \mathrm{mmol} / \mathrm{L}$ nonessential amino acids (Invitrogen). The cells were maintained in an incubator at $37^{\circ} \mathrm{C}$ in a humid atmosphere containing $5 \%$ CO2. The cultures were maintained semi-confluent to prevent cellular differentiation. The cell culture medium was changed every two days. Establishment of the FBS percentage to induce nutritional deficiency

The effects of LPT on cultured cell growth are clearly observed when the cultures are grown under conditions of nutritional deficiency. This in vitro situation is comparable to an in vivo stress condition, in which LPT has shown to be effective. Previous studies have shown that when the cells are grown in culture medium supplemented with reduced FBS concentrations (nutrition deficiency status) the cellular growth rate is significantly decreased compared with the cells cultured under optimal conditions. ${ }^{13,20}$ To establish an FBS percentage on a cell culture medium that induces a nutritional deficiency, 103 cells/well were plated into three 96-well culture plates ( 30 wells/ plate) and maintained in an incubator at $37^{\circ} \mathrm{C}$ in a humid atmosphere containing $5 \% \mathrm{CO} 2$. After $6 \mathrm{~h}$, the culture medium with 15\% FBS was replaced by culture medium supplemented with five different FBS concentrations $(15 \%, 10 \%, 5 \%, 2.5 \%$, and $0 \%$ ). The cell viability of all groups was measured 24,48 , and $72 \mathrm{~h}$ after the culture medium exchange. This analysis was based on the cell mitochondrial activity measured by the MTT reduction based on a cytotoxicity assay (Invitrogen). Immediately after the completion of the assay, the absorbance was read in a microplate reader (Biotrak II, Biochrom Ltd., Eugendorf, Austria) using a $562 \mathrm{~nm}$ filter.

\section{Laser phototherapy (LPT) protocol}

LPT was carried out with a 660-nm wavelength continuous wave diode laser (InGaAlP, Photon Lase III, DMC Equipamentos, São Carlos, Brazil). The laser irradiation was punctual and in contact with the bottom of the wells of the cell culture plate, using energy parameters listed in Table 1 . The LaserCheck power meter (Coherent, Inc., Santa Clara, USA) was 
used to verify the output power of the laser equipment. The control groups were treated under identical conditions, but the laser equipment was kept off. The experiments were set up to standardize the irradiation procedures. To minimize the distance between the laser source and the surface of the application, the irradiation was performed in contact with the bottom surface of each well. Thus, the laser beam was applied straight onto the cell monolayer, and the distance was held constant at $1 \mathrm{~mm}$. Finally, the laser irradiation was carried out in partial darkness without influence of any other light.

\section{Cell proliferation assay}

The same SHED lineage (PDH7, eighth passage) was cultured as mentioned previously. A total of 103 cells/well were seeded into four 96-well culture plates ( 24 wells/plate). These wells were distributed in the plates with the maximum possible distance between each other to avoid the interferences between the different experimental groups. After $6 \mathrm{~h}$, the culture medium was replaced according to the experimental group. The positive control group received the culture medium with 15\% FBS, whereas the negative control group and the two laser groups received the culture medium with 5\% FBS (nutritional deficiency conditions). After $12 \mathrm{~h}$, the wells of the laser groups were irradiated according to each parameter $(3 \mathrm{~J} / \mathrm{cm} 2$ and $5 \mathrm{~J} / \mathrm{cm} 2)$. These wells were irradiated again $6 \mathrm{~h}$ after the first irradiation. The cell viability of all groups was measured immediately $(0 \mathrm{~h})$ after the last laser irradiation, and 24, 48, and $72 \mathrm{~h}$ later. This analysis was based on cell mitochondrial activity measured by the MTT reduction (Invitrogen) based on the cytotoxicity assay, as described above.

\section{Statistical analysis}

The optical density data corresponding to the cell viability was obtained in six replicates and presented as the mean \pm standard error of the mean (SE). The data were compared by one-way ANOVA followed by the Tukey's test. The level of significance was set at $5 \%(\mathrm{p} \leq 0.05)$.

\section{Results}

\section{Establishment of the FBS percentage to induce nutritional deficiency}

The growth rate of SHEDs in the culture medium was supplemented with increasing FBS concentrations $(15 \%, 10 \%, 5 \%, 2.5 \%$, and $0 \%)$, and compared to establish the appropriate serum percentage for the proposed laser experiments. The growth curves are presented in Figure 1. Significant growth was observed in the cultures grown in the culture media supplemented with all tested FBS concentrations, except those grown in medium supplemented with $0 \%$ FBS. The growth of the cultures treated with culture medium supplemented with $10 \%$ FBS was similar to that of the control group (15\%) ( $p>0.05)$. When the FBS concentration was reduced to $5 \%$ and $2.5 \%$, the cell growth was significantly lower than that in the control group $(\mathrm{p}<0.05)$. On comparing these groups, it was shown that the cell growth in the $5 \%$ group was significantly higher than that in the $2.5 \%$ group in the $72 \mathrm{~h}$ period. Moreover, there were no significant differences between the $48 \mathrm{~h}$ and $72 \mathrm{~h}$ periods in the $2.5 \%$ group. Based on these results, the concentration of $5 \%$ FBS was used to induce nutritional deficiency in the second experiment.

\section{Effect of LPT on cellular growth}

The effect of LPT was analyzed in SHEDs grown in nutritionally deficient culture medium supplemented with only $5 \%$ FBS. The growth curves are presented in Figure 2. The effect of the two laser parameters tested on cell growth was compared with the results of positive (15\% FBS) and negative (5\% FBS) groups.

Table 1. Dosimetry parameters.

\begin{tabular}{lcccccc}
\hline Group & Spot area $(\mathrm{cm} 2)$ & Energy density $(\mathrm{J} / \mathrm{cm} 2)$ & Energy per point $(\mathrm{J})$ & Power $(\mathrm{mW})$ & Time per irradiation $(\mathrm{s})$ & Irradiance $(\mathrm{mW} / \mathrm{cm} 2)$ \\
\hline G1/G2 & - & - & - & - & - & - \\
G3 & 0.028 & 3 & 0.09 & 10 & 8 & 0.33 \\
G4 & 0.028 & 5 & 0.15 & 10 & 14 & 0.33 \\
\hline
\end{tabular}


In addition, the control groups were compared, which showed that the positive control group had the highest rate of cellular growth in all of the periods tested $(p<0.01)$. The cells irradiated with $5 \mathrm{~J} / \mathrm{cm} 2$ had a similar growth curve in comparison with the positive control group in the periods of 48 and $72 \mathrm{~h}$ after the laser irradiation $(\mathrm{p}>0.05)$. Both the laser groups had a significantly higher culture growth curve in comparison with the negative control group during the entire experimental period $(p<0.05)$.



Figure 1. The absorbance levels of SHED-GFP cells cultured under different percentages of FBS in relation to the time period. Different letters indicate the statistically significant differences between the groups according to one-way ANOVA ( $p<0.05)$.

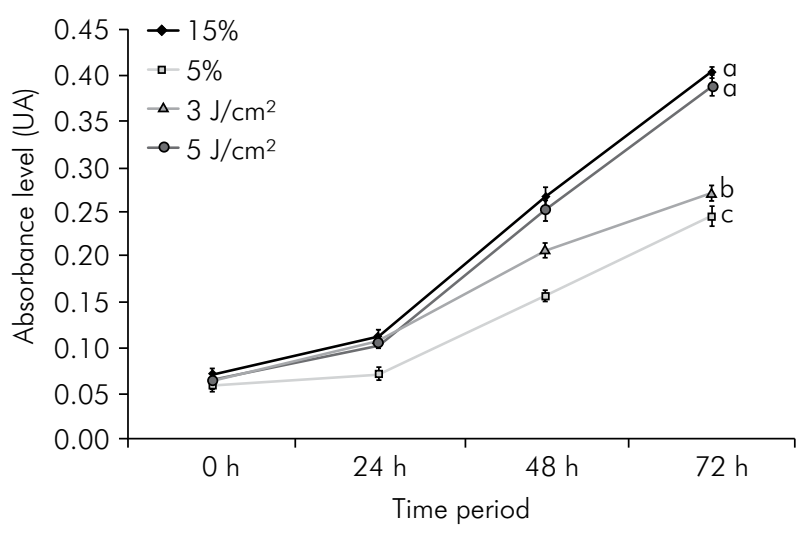

Figure 2. Absorbance levels of experimental groups in relation to the time period. Different letters indicate statistically significant differences according to one-way ANOVA $(p<0.05)$. Since the time $0 \mathrm{~h}$ period, the cellular growth in all experimental groups was significantly higher than in the negative control group ( $5 \% \mathrm{FBS})$, indicating that LPT increased the cellular growth when cultured under nutritionally deficient conditions.
However, the $3 \mathrm{~J} / \mathrm{cm} 2$ parameter did not achieve the same level of cellular growth in the positive control group.

\section{Discussion}

Tissue engineering was developed as a new alternative for pulp regeneration. ${ }^{4,7,8}$ This procedure was able to allow an immature permanent tooth with pulp necrosis to be treated with stem cells to create new pulp tissue and reestablish the apexogenesis process. ${ }^{3,5,9}$ Several in vitro studies have demonstrated the mechanisms of signaling, proliferation, and differentiation of the stem cells from the dental pulp. ${ }^{5,10,11}$ The most common procedure used recently for pulp revascularization is the creation of a blood clot inside the root canal by stimulating the bleeding of periapical tissues of the necrotic teeth. ${ }^{7}$ A previous study found that this procedure was based on the harvesting and emergence of the remaining stem cells located on the apical papilla of this tooth. ${ }^{10}$

In a perfect environment, the stem cells can proliferate and come into contact with different types of growth factors, and they can differentiate into new tissue, such as dentin or bone. ${ }^{4,5,6,7,8}$ However, it is not well known in which environmental conditions these cells will be seeded using a clinical procedure. We frequently face cases of failure in the attempt to pulp revascularization. ${ }^{7,8}$ The nutritional conditions would probably be one of the great issues for the maintenance and proliferation of DPSC. Some studies have demonstrated that LPT can increase the growth of different cellular lineages when exposed to nutritional deficiency 13-17, 21-23. However, there are few studies in the literature regarding the effects of such therapy on SHED lineages. ${ }^{20,23}$ Thus, the main objective of this study was to evaluate the effect of two LPT parameters on the proliferation of a lineage of stem cells originating from an exfoliated deciduous tooth. Based on our results, LPT is a valuable adjunct to tissue regeneration procedures.

To understand the response of these cells to LPT regarding proliferation, the first step of this study was to analyze the effect of different concentrations of fetal bovine serum in the culture medium on the growth of these cells. The induction of nutritional deficiency is a method used to simulate in vivo stress 
conditions in vitro in which LPT has been found to be effective. The results of this study found that the culture medium supplemented with various concentrations of $5 \%$ and $2.5 \%$ of FBS were able to achieve nutritional deficiency in the SHED lineage. This means that the proliferation curves of the cells under these concentrations were significantly lower than those of the cells cultured under optimal conditions (15\% FBS). The concentration of 5\% FBS was chosen for LPT experiments because the cellular proliferation under these conditions was higher than the $2.5 \%$ concentration $(\mathrm{p}<0.05)$. The FBS concentration tends to vary between each study because it depends on the cell lineage and its passage. Eduardo et al. ${ }^{20}$ achieved nutritional deficiency of their stem cell lineage using a $10 \%$ FBS concentration. In the present study, this concentration presented a growth curve similar to the control group (15\%). This difference is also explained by the possibility that stem cells originated from different donors and are associated with particular biological behaviors. In fact, a previous study from our research group demonstrated that the donor tooth conditions could influence the expression of extracellular matrix proteins. ${ }^{24}$

Several studies have demonstrated that LPT increases the growth of cells that are under nutritional deficiency. In contrast, LPT does not have a significant effect on cellular growth in cultures grown under optimal conditions. According to Karu (1986), the effect of LPT is dependent on the state of cell redox

\section{References}

1. Ritwik P, Massey C, Hagan J. Epidemiology and outcomes of dental trauma cases from an urban pediatric emergency department. Dent Traumatol. 2015;31(2):97-102. doi:10.1111/edt.12148

2. Wagle E, Allred EN, Needleman HL. Time delays in treating dental trauma at a children's hospital and private pediatric dental practice. Pediatr Dent. 2014;36(3):216-21.

3. Corbella S, Ferrara G, El Kabbaney A, Taschieri S. Apexification, apexogenesis and regenerative endodontic procedures: a review of the literature. Minerva Stomatol. 2014;63(11-12):375-89.

4. Casagrande L, Cordeiro MM, Nör SA, Nör JE. Dental pulp stem cells in regenerative dentistry. Odontology. 2011;99(1):1-7. doi:10.1007/s10266-010-0154-Z during laser irradiation12. The cellular response is weak or does not exist when the original redox potential is optimal or near optimal. In addition, the cells with a lower $\mathrm{pH}$ than normal are more sensitive to LPT than those with parameters being optimal or close to it. ${ }^{12,13,17,18,19,20}$

In this study, we used two different energy densities to analyze the effects of LPT on stem cells from deciduous teeth. Both protocols (i.e., $3 \mathrm{~J} / \mathrm{cm} 2$ and $5 \mathrm{~J} / \mathrm{cm} 2$ ) presented with significantly higher values of cellular proliferation compared with the negative control group (5\% FBS). As presented by Eduardo et al. ${ }^{20}$ using different protocols of LPT, our study demonstrated that LPT was capable of improving the growth of stem cells cultured under nutritionally deficient conditions. This reinforces the great value of LPT to achieve better outcomes in tissue engineering procedures. These results provide new insights into pulp revascularization and establish the importance of low-level LPT for these procedures.

Within the limitations of this study, we can conclude that LPT improved the growth of stem cells from deciduous teeth cultured under nutritionally deficient conditions. Therefore, LPT could be relevant as the adjunctive therapy for tissue engineering.

\section{Acknowledgements}

This study was supported by the State of São Paulo Research Foundation (FAPESP processes 2009/13483-4 and 2010/12458-3).

5. Cordeiro MM, Dong Z, Kaneko T, Zhang Z, Miyazawa M, Shi $S$, et al. Dental pulp tissue engineering with stem cells from exfoliated deciduous teeth. J Endod. 2008;34(8):962-9. doi:10.1016/j.joen.2008.04.009

6. Kerkis I, Caplan AI. Stem cells in dental pulp of deciduous teeth. Tissue Eng Part B Rev. 2012;18(2):129-38. doi:10.1089/ten.teb.2011.0327

7. Hargreaves KM, Diogenes A, Teixeira FB. Treatment options: biological basis of regenerative endodontic procedures. J Endod. 2013;39(3 Suppl):S30-43. doi:10.1016/j.joen.2012.11.025

8. Hargreaves KM, Diogenes A, Teixeira FB. Paradigm lost: a perspective on the design and interpretation of regenerative endodontic research. J Endod. 2014;40(4 Suppl):S65-9. doi:10.1016/j.joen.2014.01.023 
9. Kumar H, Al-Ali M, Parashos P, Manton DJ. Management of 2 teeth diagnosed with dens invaginatus with regenerative endodontics and apexification in the same patient: a case report and review. J Endod. 2014;40(5):725-31. doi:10.1016/j.joen.2013.10.030

10. Lovelace TW, Henry MA, Hargreaves KM, Diogenes A. Evaluation of the delivery of mesenchymal stem cells into the root canal space of necrotic immature teeth after clinical regenerative endodontic procedure. J Endod. 2011;37(2):133-8. doi:10.1016/j.joen.2010.10.009

11. Martin DE, De Almeida JF, Henry MA, Khaing ZZ, Schmidt CE, Teixeira FB, et al. Concentration-dependent effect of sodium hypochlorite on stem cells of apical papilla survival and differentiation. J Endod. 2014;40(1):51-5. doi:10.1016/j.joen.2013.07.026

12. Karu TI. [Molecular mechanism of the therapeutic effect of low-intensity laser irradiation]. Dokl Akad Nauk SSSR. 1986;291(5):1245-9. Russian.

13. Almeida-Lopes L, Rigau J, Zângaro RA, Guidugli-Neto J, Jaeger MM. Comparison of the low level laser therapy effects on cultured human gingival fibroblasts proliferation using different irradiance and same fluence. Lasers Surg Med. 2001;29(2):179-84. doi:10.1002/1sm.110

14. Pereira AN, Eduardo CP, Matson E, Marques MM. Effect of low-power laser irradiation on cell growth and procollagen synthesis of cultured fibroblasts. Lasers Surg Med. 2002;31(4):263-7. doi:10.1002/1sm.10107

15. Marques MM, Pereira AN, Fujihara NA, Nogueira FN, Eduardo CP. Effect of low-power laser irradiation on protein synthesis and ultrastructure of human gingival fibroblasts. Lasers Surg Med. 2004;34(3):260-5. doi:10.1002/lsm.20008

16. Azevedo LH, de Paula Eduardo F, Moreira MS, de Paula Eduardo C, Marques MM. Influence of different power densities of LILT on cultured human fibroblast growth : a pilot study. Lasers Med Sci. 2006;21(2):86-9. doi:10.1007/s10103-006-0379-9
17. Eduardo FP, Mehnert DU, Monezi TA, Zezell DM, Schubert $\mathrm{MM}$, Eduardo CP, et al. Cultured epithelial cells response to phototherapy with low intensity laser. Lasers Surg Med. 2007;39(4):365-72. doi:10.1002/1sm.20481

18. Chen $\mathrm{CH}$, Hung HS, Hsu SH. Low-energy laser irradiation increases endothelial cell proliferation, migration, and eNOS gene expression possibly via PI3K signal pathway. Lasers Surg Med. 2008;40(1):46-54. doi:10.1002/1sm.20589

19. Damante CA, De Micheli G, Miyagi SP, Feist IS, Marques MM. Effect of laser phototherapy on the release of fibroblast growth factors by human gingival fibroblasts. Lasers Med Sci. 2009;24(6):885-91. doi: 10.1007/s10103-008-0582-y

20. Eduardo FP, Bueno DF, Freitas PM, Marques MM, Passos-Bueno MR, Eduardo Cde P, et al. Stem cell proliferation under low intensity laser irradiation: a preliminary study. Lasers Surg Med. 2008;40(6):433-8. doi:10.1002/lsm.20646

21. Hou JF, Zhang H, Yuan X, Li J, Wei YJ, Hu SS. In vitro effects of low-level laser irradiation for bone marrow mesenchymal stem cells: proliferation, growth factors secretion and myogenic differentiation. Lasers Surg Med. 2008;40(10):726-33. doi:10.1002/1sm.20709

22. Mvula B, Moore TJ, Abrahamse H. Effect of low-level laser irradiation and epidermal growth factor on adult human adipose-derived stem cells. Lasers Med Sci. 2010;25(1):33-9. doi:10.1007/s10103-008-0636-1

23. Arany PR, Cho A, Hunt TD, Sidhu G, Shin K, Hahm E et al. Photoactivation of endogenous latent transforming growth factor- $\beta 1$ directs dental stem cell differentiation for regeneration. Sci Transl Med. 2014;6(238):238ra69.

24. Harumi Miyagi SP, Kerkis I, da Costa Maranduba CM, Gomes CM, Martins MD, Marques MM. Expression of extracellular matrix proteins in human dental pulp stem cells depends on the donor tooth conditions. J Endod. 2010;36(5):826-31. doi:10.1016/j.joen.2010.02.020 